NASA/CR-2003-212736

\title{
Wind-US Flow Calculations for the M2129 S-Duct Using Structured and Unstructured Grids
}

Stanley R. Mohler, Jr.

QSS Group, Inc., Cleveland, Ohio 
Since its founding, NASA has been dedicated to the advancement of aeronautics and space science. The NASA Scientific and Technical Information (STI) Program Office plays a key part in helping NASA maintain this important role.

The NASA STI Program Office is operated by Langley Research Center, the Lead Center for NASA's scientific and technical information. The NASA STI Program Office provides access to the NASA STI Database, the largest collection of aeronautical and space science STI in the world. The Program Office is also NASA's institutional mechanism for disseminating the results of its research and development activities. These results are published by NASA in the NASA STI Report Series, which includes the following report types:

- $\quad$ TECHNICAL PUBLICATION. Reports of completed research or a major significant phase of research that present the results of NASA programs and include extensive data or theoretical analysis. Includes compilations of significant scientific and technical data and information deemed to be of continuing reference value. NASA's counterpart of peerreviewed formal professional papers but has less stringent limitations on manuscript length and extent of graphic presentations.

- TECHNICAL MEMORANDUM. Scientific and technical findings that are preliminary or of specialized interest, e.g., quick release reports, working papers, and bibliographies that contain minimal annotation. Does not contain extensive analysis.

- CONTRACTOR REPORT. Scientific and technical findings by NASA-sponsored contractors and grantees.
- CONFERENCE PUBLICATION. Collected papers from scientific and technical conferences, symposia, seminars, or other meetings sponsored or cosponsored by NASA.

- SPECIAL PUBLICATION. Scientific, technical, or historical information from NASA programs, projects, and missions, often concerned with subjects having substantial public interest.

- TECHNICAL TRANSLATION. Englishlanguage translations of foreign scientific and technical material pertinent to NASA's mission.

Specialized services that complement the STI Program Office's diverse offerings include creating custom thesauri, building customized databases, organizing and publishing research results ... even providing videos.

For more information about the NASA STI Program Office, see the following:

- Access the NASA STI Program Home Page at http://www.sti.nasa.gov

- E-mail your question via the Internet to help@sti.nasa.gov

- Fax your question to the NASA Access Help Desk at 301-621-0134

- Telephone the NASA Access Help Desk at 301-621-0390

- Write to:

NASA Access Help Desk

NASA Center for AeroSpace Information 7121 Standard Drive

Hanover, MD 21076 
NASA/CR-2003-212736

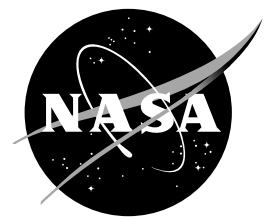

\section{Wind-US Flow Calculations for the M2129 S-Duct Using Structured and Unstructured Grids}

Stanley R. Mohler, Jr.

QSS Group, Inc., Cleveland, Ohio

Prepared for the

42nd Aerospace Sciences Meeting and Exhibit

sponsored by the American Institute of Aeronautics and Astronautics

Reno, Nevada, January 5-8, 2004

Prepared under Contract NAS3-00145

National Aeronautics and

Space Administration

Glenn Research Center 


\section{Acknowledgments}

The author wishes to thank Dr. Todd Michal and Dr. Mori Mani, the Boeing Company, for assistance in learning the

MADCAP and Wind-US software; Dr. David Marcum, MSU, for providing support for the AFLR3 software; and

Dr. Bernie Anderson, NASA GRC, for help in obtaining and interpreting the experimental data. This work was supported by the NASA Glenn Research Center under contract NAS3-00145 with QSS Group, Inc.

Trade names or manufacturers' names are used in this report for identification only. This usage does not constitute an official endorsement, either expressed or implied, by the National Aeronautics and Space Administration.

This work was sponsored by the Low Emissions Alternative

Power Project of the Vehicle Systems Program at the NASA Glenn Research Center.

Available from

NASA Center for Aerospace Information 7121 Standard Drive

Hanover, MD 21076
National Technical Information Service 5285 Port Royal Road Springfield, VA 22100 


\title{
WIND-US FLOW CALCULATIONS FOR THE M2129 S-DUCT USING STRUCTURED AND UNSTRUCTURED GRIDS
}

\author{
Stanley R. Mohler, Jr. ${ }^{*}$ \\ QSS Group, Inc. \\ Cleveland, Ohio 44135
}

\begin{abstract}
Computational Fluid Dynamics (CFD) flow solutions for the M2129 diffusing S-duct with and without vane effectors were computed by the Wind-US flow solver. Both structured and unstructured 3-D grids were used. Without vane effectors, the duct exhibited massive flow separation in both experiment and CFD. With vane effectors installed, the flow remained attached and aerodynamic losses were reduced. Total pressure recovery and distortion near the duct outlet were computed from the solutions and compared favorably to experimental values. These calculations are part of a validation effort for the Wind-US code. They also provide an example case to aid engineers in learning to use the Wind-US software.
\end{abstract}

\section{INTRODUCTION}

Until recently, the NPARC Alliance CFD flow solver WIND $^{1}$ was limited to computation on structured grids. Structured grids can require weeks or months of manual labor to generate for complex configurations. Unstructured grids are amenable to automatic grid generation, reducing delays and costs. Currently, the Alliance is incorporating a flow solver into WIND that uses unstructured grids. Coinciding with this effort, the WIND code is being renamed Wind-US. ${ }^{2}$ Wind-US solves viscous, compressible flows using structured, unstructured, and hybrid grids.

The NPARC Alliance maintains a public Web-based database of verification and validation cases that were run using WIND. The Web address is http://www.grc.nasa.gov/WWW/wind/valid/. In addition to verifying and validating the flow solver, these cases serve as tutorials that users can run in order to learn the NPARC Alliance software. Recently, Slater et $\mathrm{al}^{3}{ }^{3}$ described a series of computational studies, all using structured grids, that are being added to the verification and validation Web site. The current study may become the first validation case on the Web site to use unstructured grids.

According to the AIAA guideline, ${ }^{4}$ validation is defined as the process of determining the degree to which a model is an accurate representation of the real world from the perspective of the intended uses of the model. In the current study, the Wind-US code is used to predict total pressure recovery and distortion in a diffusing serpentine engine inlet duct. These two parameters characterize the aerodynamic effectiveness of an engine inlet. Recent research seeks to improve inlet performance through greater flow control via vane effectors and microjets. ${ }^{5-9}$

Two S-duct configurations were examined for the current study. One configuration contained 22 vane effectors arranged circumferentially around the duct wall between the two bends to provide flow control. In appearance, these vane effectors were identical to vortex generators, and are commonly referred to as such. The other configuration was identical but had no vane effectors. Flow fields were computed in both configurations for throat Mach numbers as high as 0.8. Computed values of total pressure and DC60 distortion were compared to experimental values.

Note that the NPARC Verification and Validation Web site currently contains a WIND test case for the clean M2129 S-duct computed on a structured grid, at http://www.grc.nasa.gov/WWW/wind/valid/sduct/sduct.html. The current study did not use data directly from that case, relying instead on alternative files containing the vane effector geometry.

This paper provides an overview of the NPARC Alliance and commercial software used in this study to create unstructured grids, solve the flow on them, and postprocess the results. Details are given on how Wind-US was run. The S-duct experiments are described. The CFD results are provided and compared with experiment. Finally, some conclusions are drawn.

*Aerospace Engineer, AIAA Member 


\section{OVERVIEW OF Wind-US AND RELATED SOFTWARE}

As the WIND flow solver moves beyond version 5, it is being renamed Wind-US. The "US" stands for "unstructured-structured." In addition to all the structured grid algorithms and capabilities available in WIND 5, Wind-US encapsulates the ICAT unstructured grid flow solver. ${ }^{10}$ ICAT is a cellcentered viscous, compressible flow solver originally developed for Alliance member Boeing by the CFD department of HyPerComp, Inc. (formerly the CFD department of the Rockwell Science Center). The unstructured volume grids can be tetrahedral, pentahedral (prisms and pyramids), and hexahedral. The ".dat" input file for Wind-US uses all the keywords accepted by the WIND code plus some new keywords for unstructured grid algorithms. Not all boundary conditions and turbulence models available for structured grid flow calculation are yet available for unstructured grids. However, the Alliance is working toward closing that gap.

A preliminary version of Wind-US was named BCFD, ${ }^{11}$ and was the result of merging an early version of WIND with ICAT. For the current study, BCFD 2.54 was used for the flow calculations on unstructured grids. WIND 5 was used for the structured grid calculations. Since BCFD and WIND 5 were combined into the alpha version of Wind-US as this paper was being written, the CFD method in the current study will be referred to as Wind-US.

At the time of this study, Wind-US required the input grid point coordinates to be in Common Grid (CGD) format. $^{12}$ The CGD format had been extended to include unstructured grids. There is a version of the MADCAP preprocessor, used in this study, which generates unstructured grids and outputs them in CGD file format. This version of MADCAP is proprietary and therefore not released to the public.

The proprietary version of MADCAP relies on a stand-alone code named AFLR $3^{13}$ which can be licensed from either Mississippi State University or Altair Engineering. AFLR3 is a batch code that automatically generates unstructured volume grids using the Advancing Front method with Local Reconnection. It generates tetrahedral cells throughout the entire volume of interest. An optional second phase grows prismatic cells off of viscous walls. When these prismatic cells locally grow to the same size as the preexisting tetrahedral cells into which they are growing, the prismatic growth ceases locally. The tetrahedral cells that were overtaken are replaced with the prismatic cells. The remaining tetrahedra are then locally connected with the prismatic cells.

Note that the ICEM Tetra and Prism grid generators that rely on version 4.1 .4 or greater of the ICEM output translator can output unstructured grids in CGD format suitable for Wind-US. ${ }^{14}$

The capability to read the CGNS format ${ }^{15}$ is being added to Wind-US. This enhancement will make Wind-US compatible with more grid generation packages.

Though the proprietary version of MADCAP was used in the current study, the public version available from the NPARC Alliance can open both structured and unstructured CGD files and apply boundary conditions. (The public version can also generate structured grids, but not unstructured.)

The NPARC Alliance usplit-hybrid utility was used to automatically partition unstructured volume grids into several zones. Wind-US distributes these zones across multiple cpu's for parallel processing.

Post processing and flow visualization were accomplished using CFPOST $^{16}$ as well as Fieldview. CFPOST, available from the NPARC Alliance, reads structured and unstructured CGD and CFL files. It provided a command-based grid and flow visualization capability and provided area-averaged values of Mach number, pressure recovery, and mass flow rate across selected stations. Fieldview is licensed from Intelligent Light. The Alliance has a special file reader that enables Fieldview to read unstructured CGD and CFL files. Fieldview was used for grid and flow visualization in this study.

Ensight 7.6 by Computational Engineering International was used successfully to read in the unstructured CGD file and produce images of the unstructured grid. However, this author was unable to visualize the flow solution with Ensight-it did not completely read the unstructured CFL file.

\section{EXPERIMENTAL APPROACH}

Under a joint program between NASA and the UK Ministry of Defense, an S-shaped duct with circular cross section was tested in the DRA/Bedford $13 \times 9 \mathrm{ft}$. wind tunnel. ${ }^{5,6}$ The S-duct was labeled M2129, and had the geometry of the AGARD Fluid Dynamics Panel Working Group 13 test case 3. ${ }^{17}$ The goal of the experimental program was to investigate the control of total pressure recovery and distortion at the engine face of a serpentine inlet. A station near the end of the duct was deemed the engine face, or Aerodynamic Interface Plane (AIP). Flow control was attempted by installing rings of vane 
effectors, sometimes referred to as vortex generators, around the sides of the duct.

Strictly speaking, these vanes should not be referred to as "vortex generators" since their mode of operation is not one of mixing high-energy flow with low-energy flow, an approach used to prevent flow separation at some design point. ${ }^{18}$ Instead, vane effectors generate a secondary flow pattern that counteracts the formation of a duct vortex. Total pressure recovery is only marginally improved by this approach, but the range of inlet operating conditions is enlarged.

Several vane effector configurations were tested. Measurements were made of the levels of total pressure recovery as well as distortion at the engine face. Distortion was quantified using the DC60 definition. ${ }^{19}$ This definition represents the difference between the mean total pressure for the entire engine face and the mean total pressure for the worst 60degree sector of the engine face.

The vane configuration that most effectively reduced flow distortion over the range of throat Mach numbers studied (0.2 to 0.8 ) was labeled "VG170." This configuration was the focus of Anderson's study in [5] and is the only vane configuration used in the current study.

Figure 1 shows a side view of the M2129 S-duct with the VG170 vane configuration as represented for CFD. The "clean" duct configuration had no vane effectors and is referred to as the baseline.

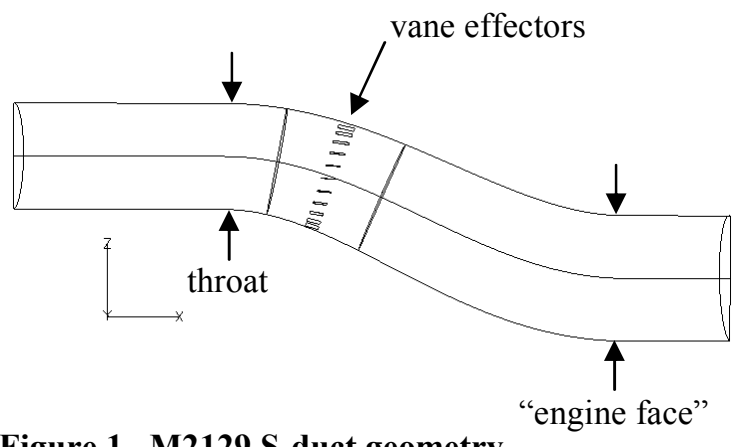

Figure 1. M2129 S-duct geometry

The S-duct was approximately 2 feet in length. The inlet throat was defined as the station at the end of the straight, constant-area section of the duct, immediately upstream of the bend. The throat diameter was approximately 5.06 inches. The "engine face", or AIP, was considered to be at the station 1.6055 feet downstream of the throat station, where the duct straightens out again. The exit diameter was 6 inches. The duct offset was 5.4 inches. A centerbody, not depicted, protruded upstream from the duct outlet and extended through the engine face. The cross-sectional area of the centerbody was about $7 \%$ of the total cross-sectional area of the engine face.

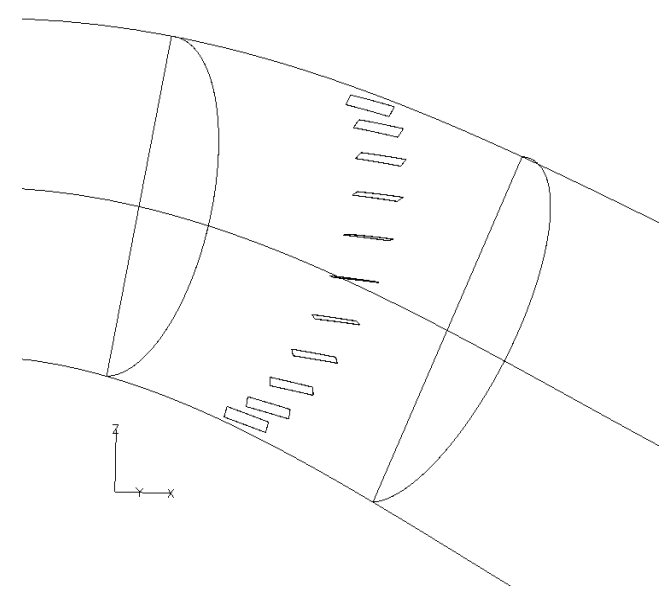

Figure 2. Vane effectors, VG170 configuration

Figure 2 shows a close-up of the vane effectors in configuration VG170 used in this study. The VG170 configuration contained 11 vane effectors per half duct, located two inlet radii downstream of the inlet throat. The vane effectors were distributed around a $157.5^{\circ}$ sector per half duct spaced $15^{\circ}$ apart. Each vane effector was a flat plate of aspect ratio 0.25 (height/chord) where the chord was approximately 0.7 inches. The incidence angle of each blade was $16^{\circ}$. The incidence was such as to turn the flow near the wall away from the bottom of the duct.

Figure 3 shows a photograph of the M2129 S-duct installed in the DRA tunnel. Figure 4 shows the duct split open revealing the vane effectors.

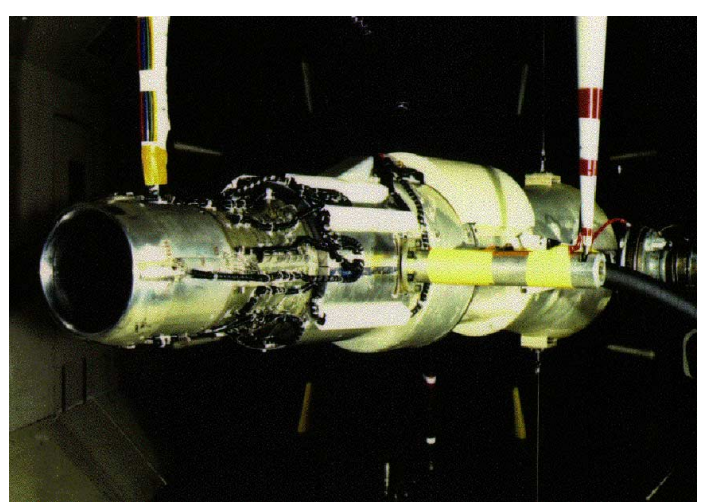

Figure 3. M2129 inlet installed in DRA tunnel 


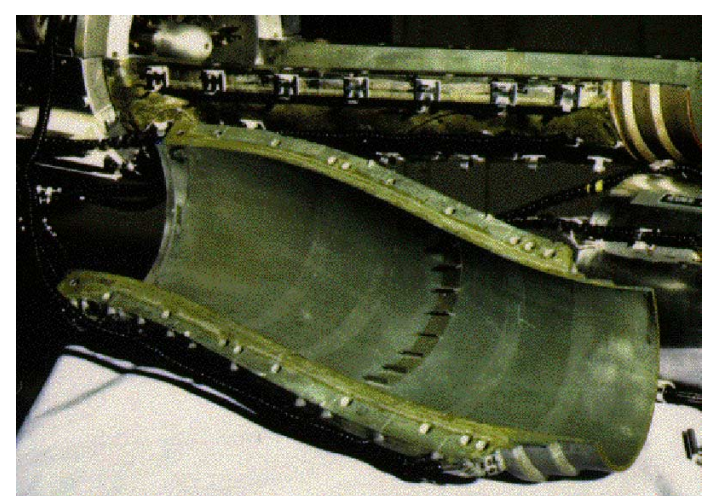

Figure 4. Interior of M2129 S-duct revealing vane effectors

The tunnel was run at near-atmospheric total conditions. Inlet flow conditions were characterized by the area-averaged throat Mach number. Throat Mach numbers between 0.2 and 0.8 were run. According to Reference [5], experience has shown that throat Mach numbers below 0.4 are unnecessary to study.

The area-averaged total pressure recovery and DC60 data were derived from a 72-probe pitot rake positioned at the engine face. Figure 5 depicts the relative probe locations.

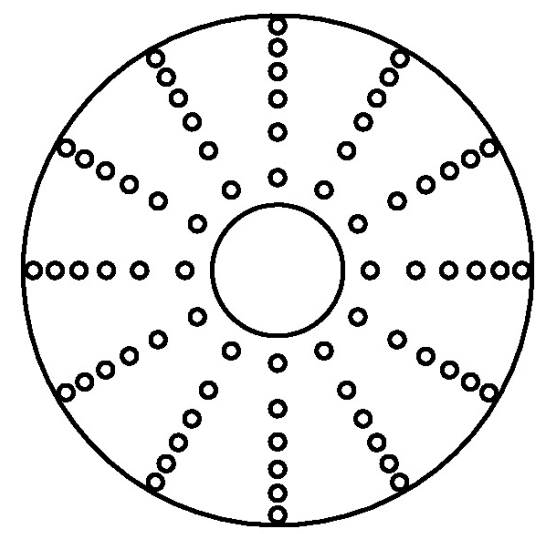

Figure 5. Pitot rake probe positions for M2129 tunnel tests

The throat Mach number was backed out from the rake data as well.

The baseline duct (no vane effectors) exhibited massive separation downstream of the bend. This separation produced total pressure losses and significant distortion at the engine face. The VG170 vane effectors greatly reduced distortion and improved total pressure recovery somewhat. Further details are discussed in Section 5.
References [5] and [6] state that vane effectors used in earlier experiments with the M2129 failed to reduce engine face distortion by as much as was expected due to incorrect CFD predictions of flow separation in the clean duct. Subsequently, design of the improved vane effector configurations, such as VG170, relied on the results of the earlier experiments rather than CFD. Whereas it is a primary goal of CFD to reduce the need for experiments, the current study attempts to renew calculations of the challenging flow seen in these experiments with the hope of good agreement between computed and actual aerodynamic performance.

\section{COMPUTATIONAL APPROACH}

\subsection{Introduction}

Section 2 provided an overview of the various software tools associated with Wind-US. This section will describe specifically how those tools were used to generate the unstructured grids for this study, and how the Wind-US flow solver was run. The subsections to follow cover important aspects of the CFD process identified in the NPARC Web-based validation tutorial. ${ }^{20}$

\section{$\underline{4.1 \text { Grid Generation }}$}

Geometrical descriptions of two configurations of the M2129 S-duct were available in the form of PLOT3D grid files. One file contained a single zone with 307,671 grid points $(69 \times 91 \times 49)$ for the baseline configuration and is shown in Figure 6. The axial grid plane that lies in the engine face can be seen in the figure.

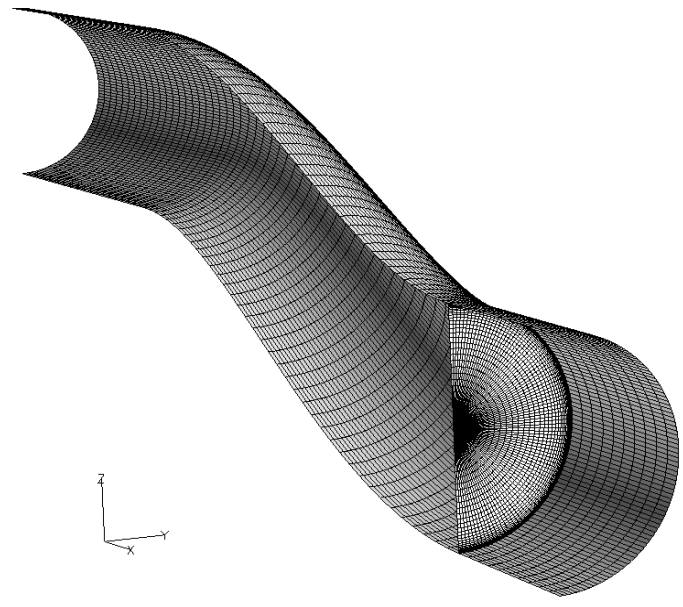

Figure 6. Structured grid representation of the baseline M2129 S-duct 


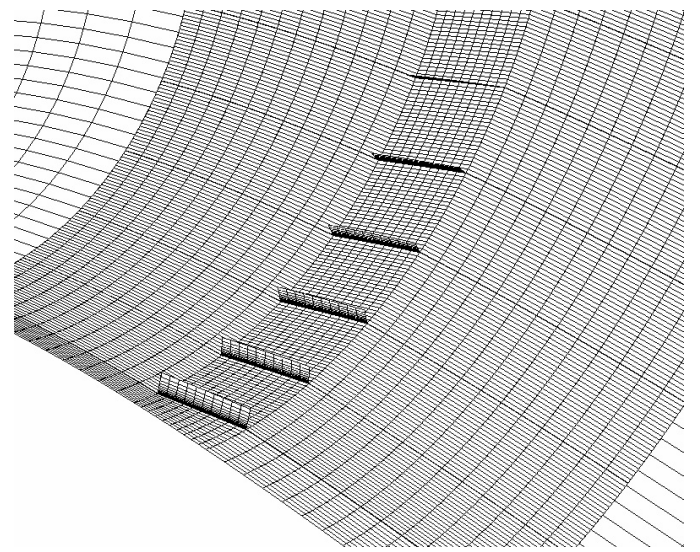

Figure 7. Vane effectors embedded in the VG170 structured grid

The other PLOT3D file contained 3 zones and about 677,940 grid points, describing the S-duct with the eleven VG170 vane effector fins embedded in the grid as internal walls. Figure 7 shows some of these internal walls.

The provided grids did not model the centerbody or the inlet lips. In Reference [5], the centerbody was not modeled by CFD, and was likewise not modeled in the current study. The cross-sectional area of the centerbody was about $7 \%$ of the total cross-sectional area of the engine face.

A straight, 10.14 inch long constant-area section had been put in at the upstream end of the duct in order to allow a CFD code to develop a boundary layer. At the duct exit, a straight, 5.07-inch-long constant-area section had been added to push the computational boundary aft of the engine face.

For the current study, a structured grid was used directly only for flow calculations on the baseline configuration (no vane effectors). The single-zone grid was used unmodified (307,671 grid points). The NPARC Alliance CFCNVT utility was used to convert the PLOT3D file to structured CGD format for input to the structured flow solver in Wind-US.

The presence of numerous small physical features in a geometry can often complicate and prolong the structured grid generation process. Though a simple structured grid was possible for the M2129 S-duct with its vane effectors, such is often not the case. Consequently, the presence of these vane effectors provided an opportunity to demonstrate the unstructured alternative of automatic volume grid generation.
The beginning step for the unstructured grid generation was the extraction of the boundary surfaces from the PLOT3D grid file. The upstream, downstream, wall, and symmetry plane surfaces were extracted by copying the min and max grid planes in the $\mathrm{I}, \mathrm{J}$, and $\mathrm{K}$ directions to a new PLOT3D file. The grid subsets defining the vane effector surfaces were similarly copied into the new PLOT3D file. MADCAP was then used to convert the new PLOT3D file to Common Surface File (CSF) format.

Once accessible to MADCAP in CSF format, the surfaces defining the vane effectors were modified slightly. The root section of each vane effector was given some thickness while the leading and trailing edges as well as the tip section retained 0 thicknesses. The maximum thickness-to-chord ratio was tiny, approximately $0.3 \%$. This thickness was provided in order to prevent possible difficulties with the AFLR3 3-D unstructured grid generator. Note, however, that a newer version of AFLR3, not available in time for this study, is expected to be free of such difficulties, allowing embedded surfaces of zero thickness.

At this point, unstructured surface grids were generated on all the structured boundary surfaces using the 2-D AFLR algorithm built into the proprietary version of MADCAP. The details of this process are not described here. Suffice it to say that the resulting unstructured surfaces, consisting of triangles, together defined a closed surface that completely enveloped the volume that was to be filled with unstructured grid cells.

Note that the process of generating unstructured surface grids in the proprietary version of MADCAP would have been much more automated had the original geometry been available as an IGES file. However, no utility was available to the author to convert the PLOT3D surfaces to an IGES form suitable for MADCAP.

Two enclosing unstructured surface grids were generated in MADCAP. The first was devoid of vane effector surfaces in order to generate a grid for the baseline (clean) configuration. The second contained the 11 vane effector surfaces of the VG170 configuration.

Unstructured volume grids in this study were generated by the AFLR3 code described in Section 2. The input files for AFLR3, prepared by the proprietary version of MADCAP, contained the enveloping unstructured surface grids in a format unique to AFLR3. AFLR3 was run at the command line with options chosen to generate layers of prismatic cells near viscous walls with an initial spacing of $0.6 \mathrm{e}-5$ (feet) and a maximum growth ratio of 
1.4. This wall spacing was taken from the supplied PLOT3D files which were designed for a $y^{+}$of about 0.5 at the higher throat Mach numbers (approximately 0.7 ).The proprietary version of MADCAP converted the unstructured volume grids produced by AFLR3 into the CGD format for input into Wind-US.

The final unstructured grid for the baseline configuration had about 830,000 volume grid cells. The grid was labeled "M2129-u-base-0", where the "u" signifies an unstructured grid, and the " 0 " can later be incremented if an alternative grid is ever created. The VG170 grid, referred to as "M2129-uvg170-0", had about 2,300,000 volume cells.

Figure 8 shows the upstream, downstream, and wall boundaries of the unstructured volume grid. One can see the viscous packing near the wall.

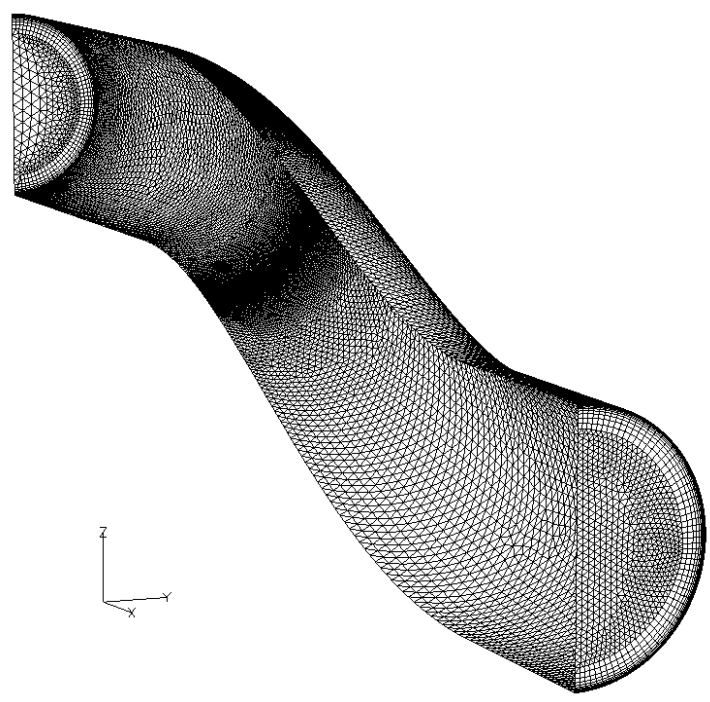

Figure 8. Unstructured grid representation of the M2129 S-duct with vane effectors

Figure 9 shows a close-up of the 11 vane effectors. The unstructured surfaces for the baseline configuration were identical to those in the figure except for the replacement of the section containing the vane effectors with a section with a smooth wall.

Figure 10 is an even closer view, showing two vane effectors.

Figure 11 shows a cross section of the volume grid where the planar intersection cuts through some of the vane effectors.

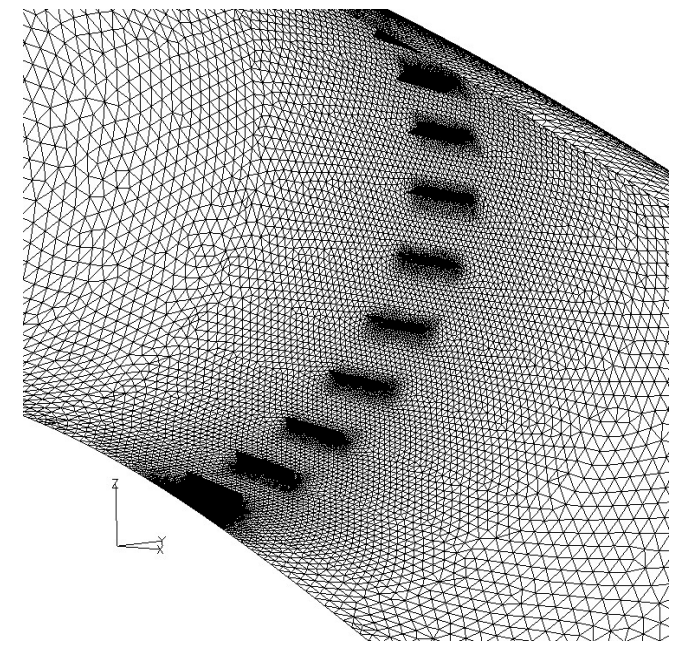

Figure 9. Vane effectors in the unstructured grid

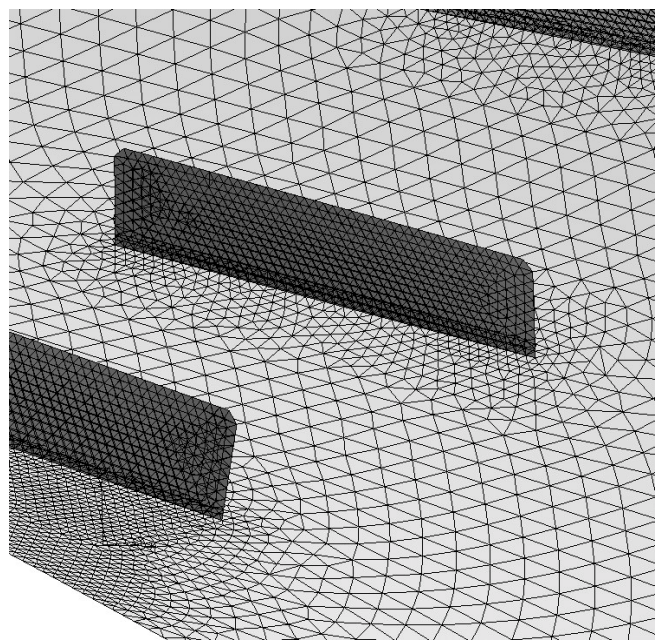

Figure 10. Close up of vane effectors in the unstructured grid

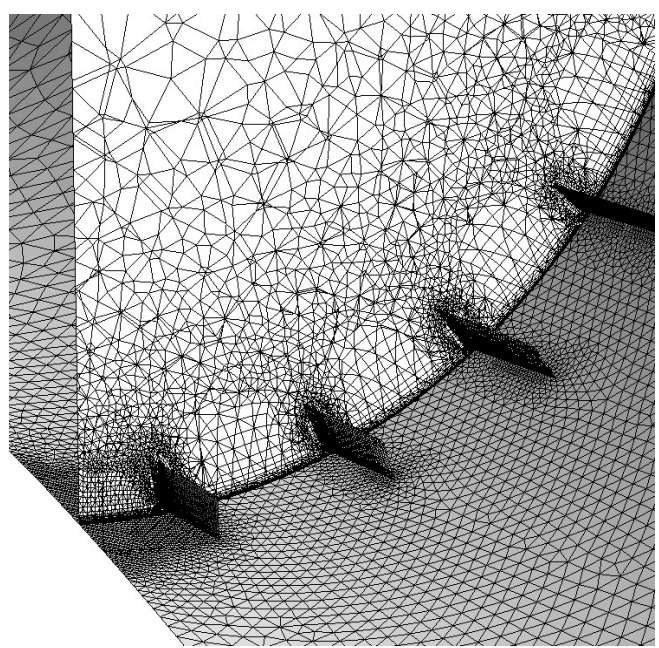

Figure 11. Axial slice through the unstructured volume grid near vane effectors 


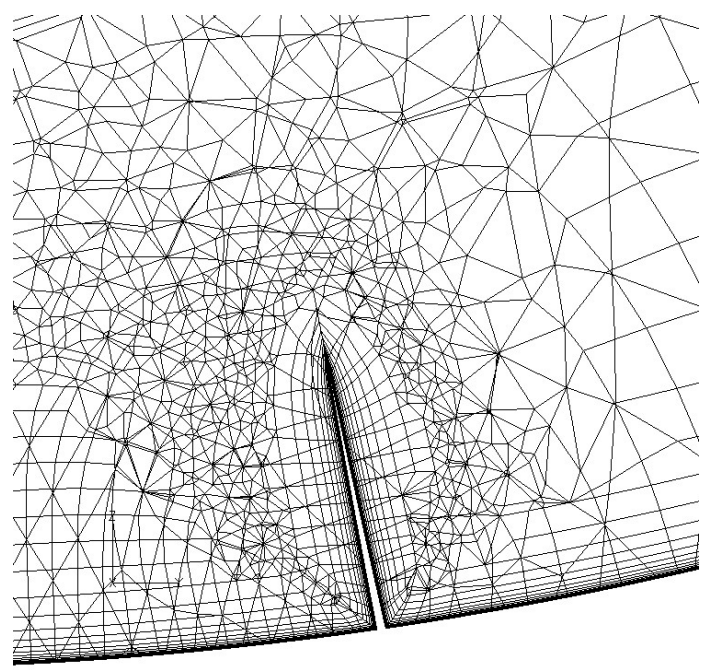

Figure 12. Slice of volume grid through one vane effector

Figure 12 is a close-up of a slice through one vane effector. The small thickness at the blade root is visible. Note the severe degree of grid bending in the viscous packing around the vane effector.

In Reference [5], the vane effectors were modeled using an inviscid wall BC. Such an approach would have reduced the number of grid cells and computation times in the current study. However, at the time of this study, the AFLR3 volume grid generator could not treat the vane effectors as "constraint surfaces" to be intersected by the viscous packing. Consequently, the only option was to run the packing along and around each vane effector. A newer version of AFLR3 is supposed to avoid this shortcoming.

The usplit-hybrid utility was used to automatically break the unstructured grid into multiple zones of approximately equal cell count for parallel processing with Wind-US. Zones near the vane effectors are smaller in volume due to the smaller cell sizes there. Figure 13 shows the VG170 configuration split into 8 zones distinguished by color.

Figure 14 shows a closer view of the grids. The "crinkle surface" at the left side of the figure shows the transition from prismatic cells in the viscous packing near the wall to tetrahedral cells in the isotropic region.

Figure 15 shows a perspective of the VG170 grids that includes the symmetry plane. Figure 16 shows the symmetry plane in profile.

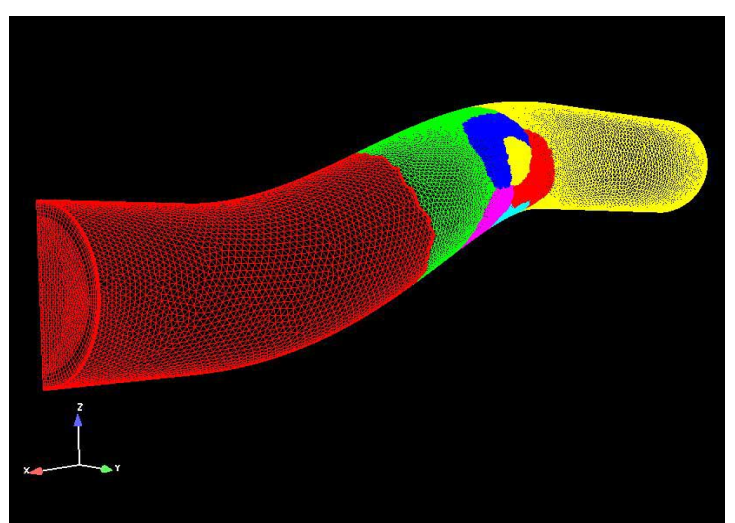

Figure 13. Unstructured volume grid split into 8 zones, VG170 configuration

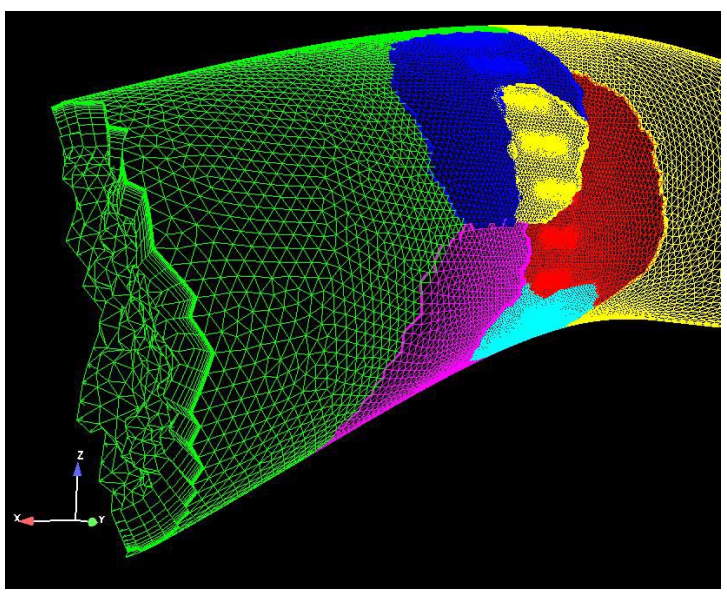

Figure 14. Crinkle surface

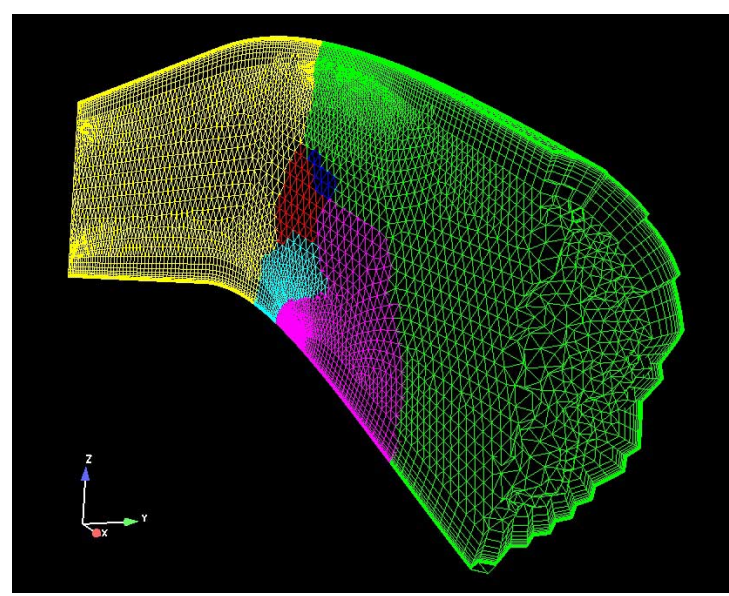

Figure 15. Crinkle surface and symmetry plane 


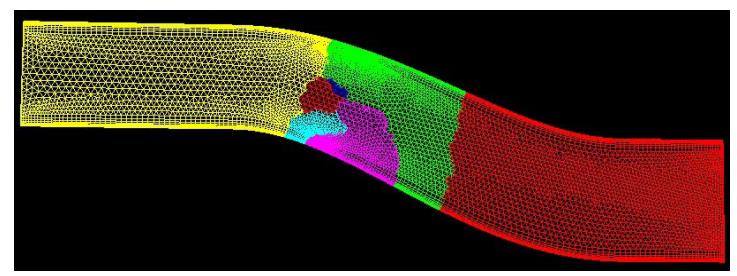

Figure 16. Symmetry plane

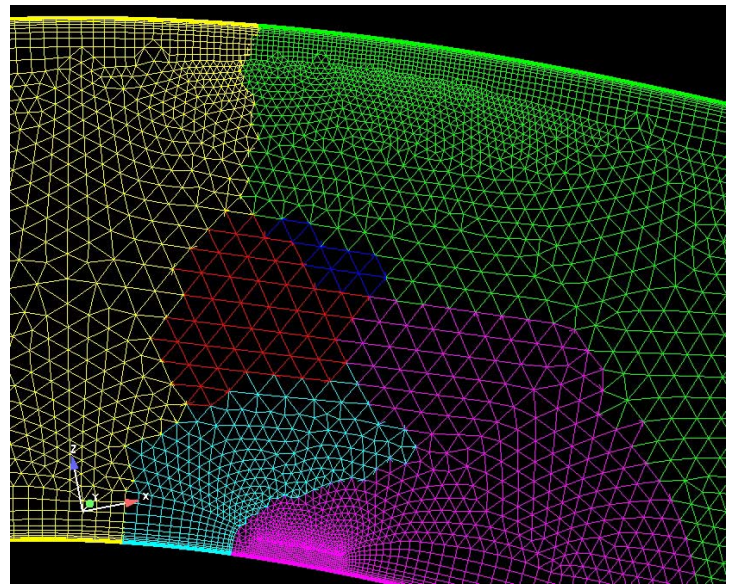

Figure 17. Bend region of symmetry plane

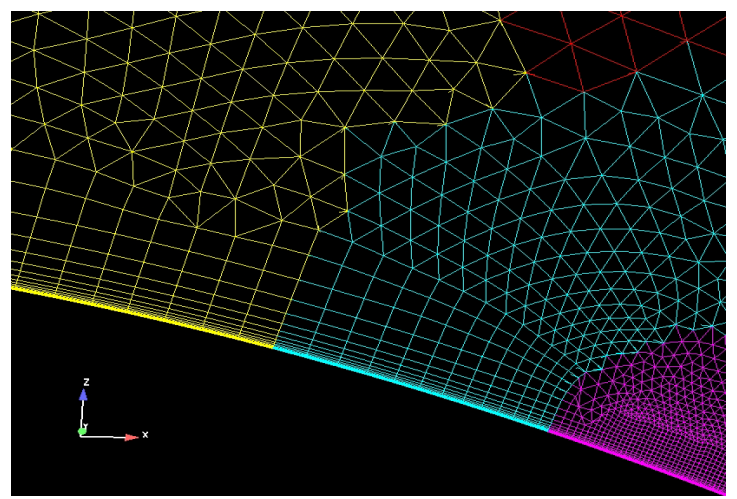

Figure 18. Transition between prismatic cells and tetrahedra in the symmetry plane

Figure 17 is a close-up in the bend region. One can see how the AFLR3 code automatically transitioned from prismatic cells to tetrahedra while marching away from the wall.

Figure 18 zooms into the vicinity of a vane effector.

Images of the 5 unstructured zones of the baseline configuration are not shown. These grids were similar to the VG170 grids except near the vane effectors.

The current study did not attempt to examine sensitivities of the flow solution to grid resolution. Therefore no further grids were generated.

\subsection{Boundary Conditions}

For both structured and unstructured grid flow solutions, the M2129 S-duct was treated as an internal flow problem, making use of the Wind-US Arbitrary Inflow and Outflow boundary conditions as well as viscous walls. A symmetry plane bisected the duct obviating the need to model both halves. A reflection plane boundary condition was imposed on the symmetry plane.

At the inflow plane, uniform total pressure and temperature values were imposed. These values were approximately sea-level standard: $14.667 \mathrm{psi}$ and $517^{\circ} \mathrm{R}$.

At the outflow plane, a uniform static pressure was imposed that produced a throat Mach number between 0.4 and 0.8 depending on the case being run. The chosen exit pressures were initially estimated by use of inviscid relationships. For later calculations, exit pressures were estimated by examining completed flow solutions.

\subsection{Initial Conditions}

For all CFD calculations, the initial flow field was uniform in the axial direction $(+x)$. The total pressure and temperature values at the inflow boundary were imposed at all grid points. The initial Mach number was set approximately equal to the expected throat Mach number (ranging between 0.4 and 0.8 ).

\section{$\underline{4.4 \text { Computational Strategy and Algorithms }}$}

CFD solutions for the baseline configuration were computed on both structured and unstructured grids. However, solutions for the VG170 configuration were only computed on an unstructured grid.

The Wind-US flow solutions on structured grids used the default second-order Roe upwind-biased differencing scheme on a single zone. The variable time step size was set by specifying a CFL number of 2.0. Though the Menter Shear-stress Transport (SST) turbulence model is a current favorite, the Spalart-Allmaras (S-A) turbulence model was used because it alone was available in both the structured and unstructured flow solvers in Wind-US. However, one structured grid case was run using SST.

The Wind-US flow solutions on unstructured grids were computed using the Rusanov second-order cell-centered right hand side option, on multiple zones. The implicit Gauss left hand side was used with 4 subiterations per iteration. Smoothing was turned on. The time step size was set by specifying a CFL number of 50 . Zones were coupled using high-order Roe coupling. The S-A turbulence model was used. For the baseline configuration, variable time stepping and the default 
smoothing parameters were used. However, for the VG170 configuration, some zones failed to converge unless constant time stepping and increased dissipation were selected. The parameter values are provided in the next section.

Note that a vortex generator model is being installed into Wind-US. ${ }^{21,22}$ This model was not used for the current study.

All CFD runs converged as judged by plots of the L2 residuals of the Navier-Stokes solvers. A run was considered converged when the residuals had visibly dropped by several orders of magnitude and then maintained a relatively constant level in each grid zone.

\subsection{Input Parameters}

The input parameters were supplied via Wind-US .dat files. The .dat file for one typical run of the structured flow solver is shown below:

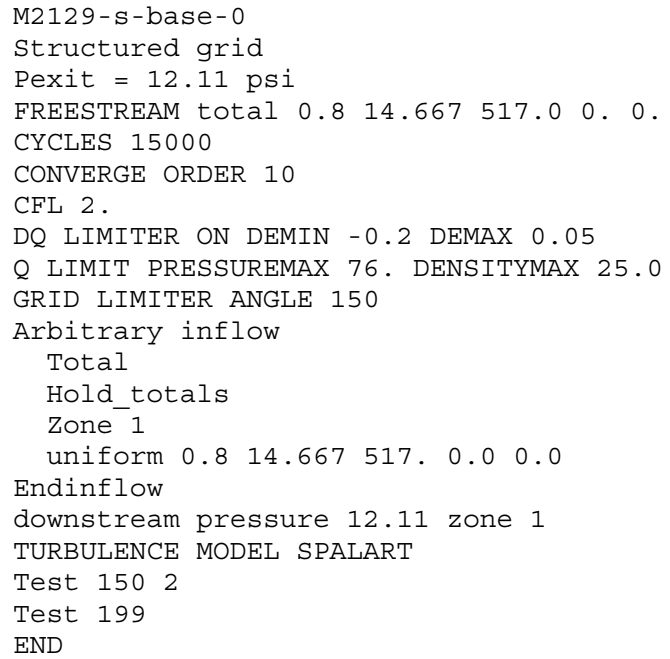

The dat file for one typical run of the unstructured flow solver for the baseline configuration was as follows:

M2129-u-base-0-5zones

Unstructured grid

Pexit $=12.07 \mathrm{psi}$

FREESTREAM total $0.8 \quad 14.667517 .0 .0$.

CYCLES 15000 print frequency 10

CONVERGE ORDER 10

CFL 50 .

ITER_CYCLE 2 print frequency 10

RHS Lax Second CELLCENTERED

IMPLICIT UGAUSS SAVE_JACOBIAN BLOCK

SUBITERATIONS 4

SMOO SECOND 0.25 FOURTH 1.5 SMLIMT 2.5

TIMEMARCHING VARIABLE-DT DTRATIO 1000.0

COUPLING MODE ROE HIGH

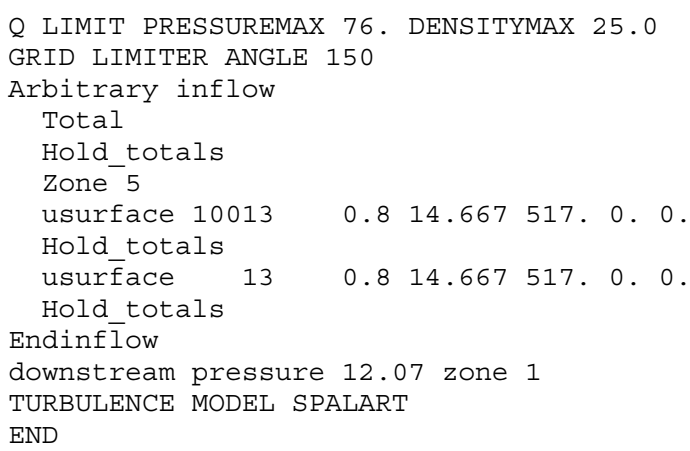

For unstructured grids, the SMOO keyword shown above provides these three parameters: the flux dissipation (0.25), Jacobian dissipation (1.5) and the gradient slope limiting (2.5). Note that the Hold totals keyword appears three times due to an anomaly in BCFD 2.54. Any newer version of Wind-US requires only the first of the three occurrences of Hold totals. Also, the "RHS Lax" keywords were renamed "RHS Rusanov" in the subsequent version of Wind-US.

To obtain convergence for the VG170 configuration, it was necessary to run constant time stepping, increase the flux dissipation, and decrease the slope limiter. Consequently, the .dat file differed from that of a baseline case by the substitution of the following two lines:

SMOO SECOND 0.4 FOURTH 1.5 SMLIMT 1.5 TIMEMARCHING CONSTANT-DT DTRATIO 100.0

\subsection{Post-processing}

From the Wind-US flow solutions, post processors extracted area-averaged throat Mach number, engine face total pressure recovery and DC60 distortion, contour plots of Mach number and pressure, as well as streamline plots.

For each Wind-US run, the CFPOST utility was used to compute a pair of data: the area-averaged Mach number at the throat, and area-averaged total pressure recovery at the engine face. After all runs were complete, plots of recovery were compared with experiment.

For each Wind-US run computed on structured grids, the DC60 distortion at the engine face was computed using a custom utility named CFACE used in Reference [5]. For runs computed on unstructured grids, the CFPOST utility was used to interpolate the flow solution onto a dense 56 x 57 structured grid for input to CFACE. Plots of DC60 were compared with experiment.

Contour plots of total pressure at the engine face were produced using Fieldview for both CFD and experiment. For CFD, Fieldview was also used to make contours plots of computed Mach number and total and static pressures in the symmetry plane. 
Streamlines and simulated surface oil flow traces were generated from the CFD solutions using Fieldview to reveal flow features.

\section{RESULTS}

\subsection{Introduction}

Both the structured and unstructured flow solvers in Wind-US were run as described in Section 4. For each duct configuration, several flow solutions were computed with throat Mach numbers ranging from about 0.4 to about 0.8 . The validity of the flow solutions was assessed using validation criteria identified in References [3] and [20]. These criteria included convergence of the flow solver, solution consistency, and comparison with experiment. Experimental values of total pressure recovery and DC60 distortion were used for the comparison. The spatial convergence criterion was not used in this study, but is discussed. Uncertainty and error in the calculations are also discussed. Flow visualizations were created in order to reveal the flow physics.

\section{$\underline{5.2 \text { CFD Run Matrix }}$}

Table 1 presents a run matrix of all the CFD cases. The type of grid used is designated by "S" for structured and " $U$ " for unstructured. "P $P_{\text {exit }}$ " identifies the static pressure that was imposed at the outflow boundary. All calculations used the S-A turbulence model except for one identified as using the SST model. The throat Mach numbers were determined after the calculations were completed but are provided in the table for reference.

\begin{tabular}{|c|c|c|c|c|}
\hline Config. & $\begin{array}{l}\text { Grid } \\
\text { Type }\end{array}$ & $\begin{array}{l}P_{\text {exit }} \\
\text { (psi) }\end{array}$ & \begin{tabular}{|c|} 
Turb. \\
Model
\end{tabular} & $\begin{array}{c}\text { Throat } \\
\text { Mach No.* }\end{array}$ \\
\hline \multirow[t]{10}{*}{ Baseline } & \multirow[t]{6}{*}{$\mathrm{S}$} & 12.11 & \multirow[t]{2}{*}{ S-A } & 0.80 \\
\hline & & 12.34 & & 0.74 \\
\hline & & 12.34 & SST & 0.73 \\
\hline & & 12.63 & \multirow{11}{*}{ S-A } & 0.67 \\
\hline & & 12.86 & & 0.62 \\
\hline & & 13.76 & & 0.40 \\
\hline & \multirow[t]{8}{*}{$\mathrm{U}$} & 12.07 & & 0.78 \\
\hline & & 12.56 & & 0.67 \\
\hline & & 12.86 & & 0.61 \\
\hline & & 13.76 & & 0.40 \\
\hline \multirow[t]{4}{*}{ VG170 } & & 12.10 & & 0.77 \\
\hline & & 12.37 & & 0.70 \\
\hline & & 12.86 & & 0.59 \\
\hline & & 13.76 & & 0.38 \\
\hline
\end{tabular}

\subsection{Hardware Run Times}

Most of the calculations were run on the NASA GRC "ziti" cluster, consisting of 8 nodes connected by Gigabit Ethernet. Each node had two AMD AthlonMP 1600+ processors at $1400 \mathrm{MHz}$ and $1.5 \mathrm{~GB}$ of RAM. The 5 unstructured zones of the baseline calculation $(830,000$ cells) were distributed among 5 processors in 3 nodes. Running dedicated, the wall clock time to perform 10,000 iterations was about 21 hours, i.e., 22,000 celliterations/sec/cpu.

Some calculations were run on a dedicated SGI Octane2 workstation with two $600 \mathrm{MHz}$ R14000 processors and 2 GB of RAM. The 5 unstructured zones of the baseline configuration took 3.5 days of wall clock time to do 10,000 iterations, i.e., 13,700 cell-iterations/sec/cpu.

For single-zone structured grid calculations, this same SGI computed 5,200 iterations per day, i.e., 18,500 gridpoint-iterations/sec/cpu.

\subsection{Convergence Histories}

All flow calculations were run until the L2 residuals of the Navier-Stokes flow solver had dropped several orders of magnitude and then remained relatively level for several thousand iterations.

Figure 19 shows a representative plot of the time history of the L2 residuals for the 5 zones of the unstructured baseline case.

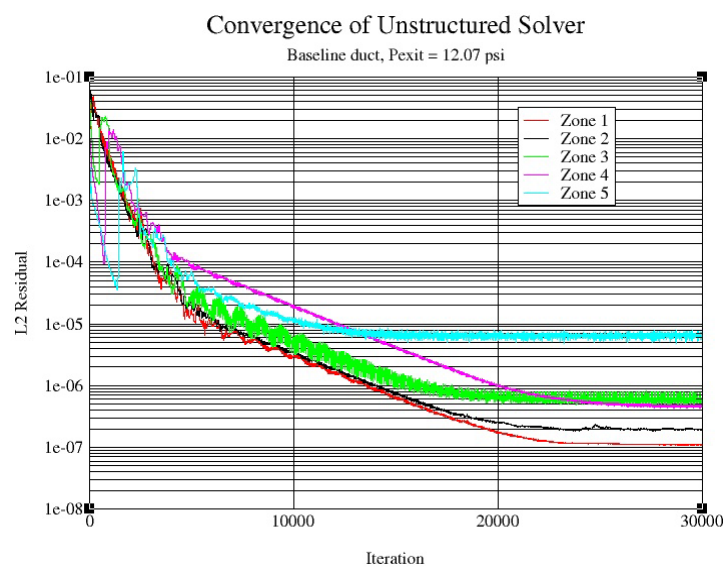

Figure 19. Convergence history of Wind-US unstructured flow solver 


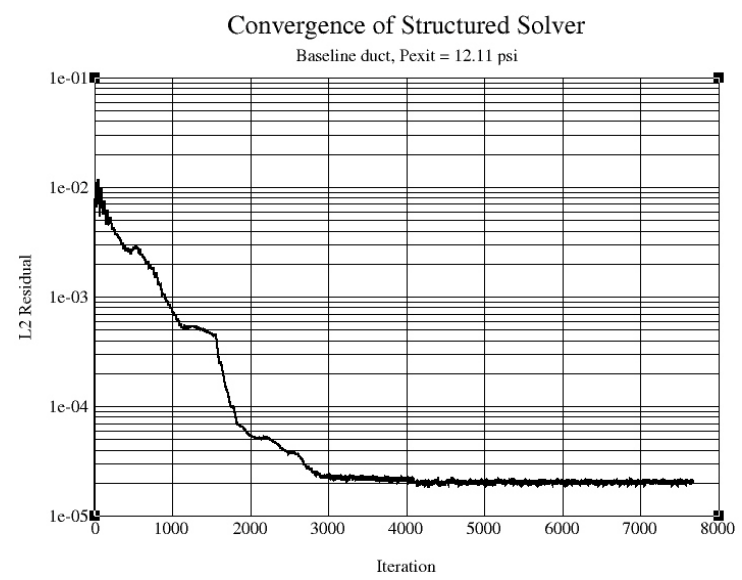

Figure 20. Convergence history of Wind-US structured flow solver

Figure 20 plots the L2 residuals for the single zone of a structured grid case. Despite using a much larger CFL, the unstructured calculation required about 6 times as many iterations to converge as the structured calculation. However, a more direct measure of convergence might be to monitor the time history of engineering quantities such as integrated aerodynamic forces on computational boundaries. Toward that end, a future study might make use of the LOADS input keyword of Wind-US.

\section{$\underline{5.5 \text { Solution Consistency }}$}

For each CFD solution, the mass flow rates at 4 stations throughout the duct were checked for consistency. The CFPOST utility provided these values by integrating the mass flux at the grid inflow boundary, the throat, the engine face, and the grid outflow boundary. For each flow solution, agreement was within approximately $0.1 \%$ or less.

\subsection{Spatial Convergence}

A complete CFD validation study requires inclusion of a grid refinement study. Flow solutions would be computed on a series of grids with successively finer resolution. The grid would be considered as sufficiently refined (spatially converged) to resolve the flow field when further refinement does not appreciably change the flow solution. For structured grids, a single refinement step is normally done by inserting an additional grid plane between each adjacent pair of existing grid planes, in each direction. No grid refinement was done for the current study, but will hopefully be done in a future study.
5.7 Comparisons between CFD and Experiment: Baseline Configuration

The area-averaged total pressure recoveries and DC60 distortions computed by CFD at the engine face of the baseline duct were compared to experimental values over a range of throat Mach numbers. Figure 21 shows total pressure recoveries. Figure 22 similarly plots DC60.

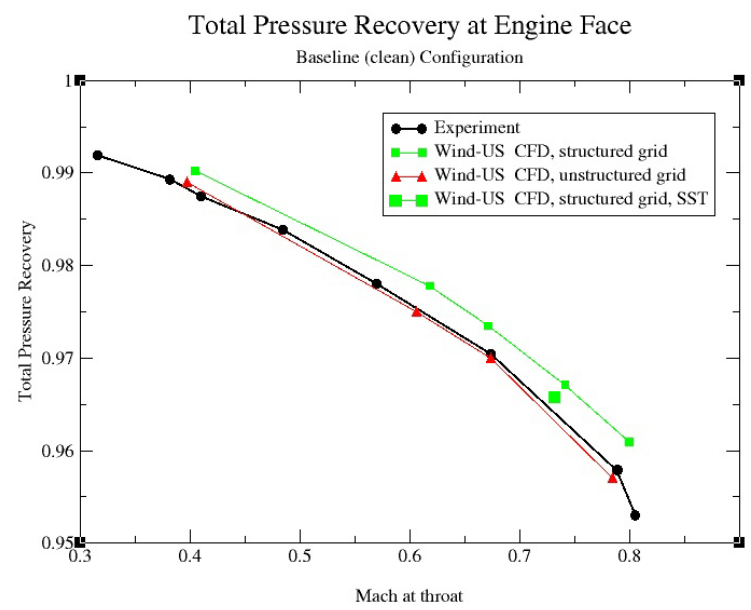

Figure 21. Effect of throat Mach number on total pressure recovery at the engine face - baseline configuration

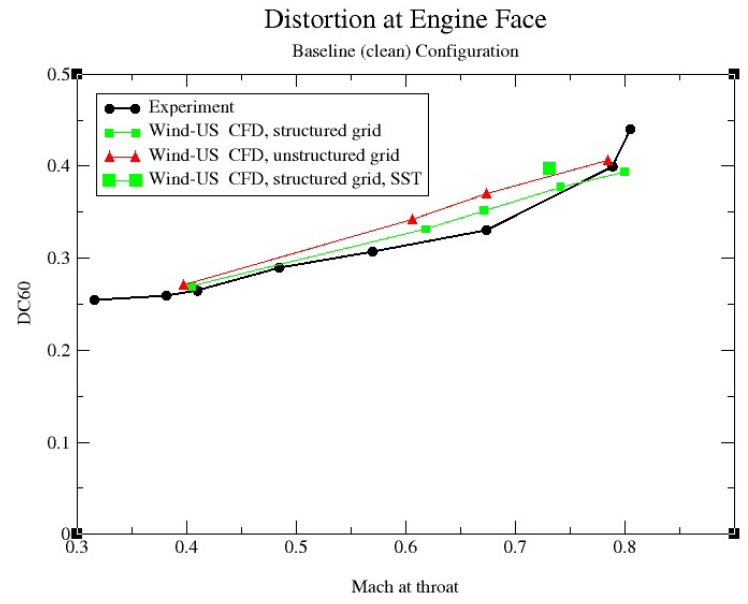

Figure 22. Effect of throat Mach number on DC60 distortion at the engine face - baseline configuration

The Wind-US calculations of recovery and distortion are seen to agree well with experiment. However, the unstructured and structured solvers appear to disagree with each other somewhat. It is not known how much of this disagreement is due to differences between the structured and unstructured grids, differences between the structured and unstructured flow solvers, and postprocessing concerns. Section 5.9 addresses the 
post-processing issue. Running both the structured and unstructured solvers on the same, structured grid might resolve these issues in the future.

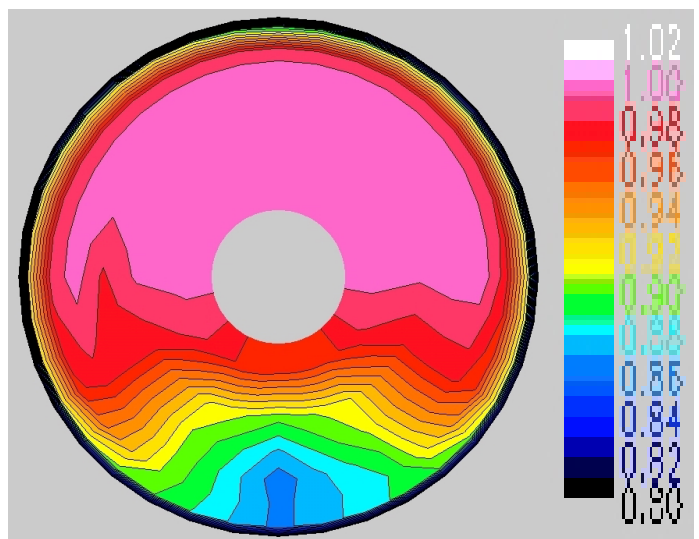

Figure 23. Experimental total pressure recoveries at the engine face (baseline configuration, Mach 0.79 at throat)

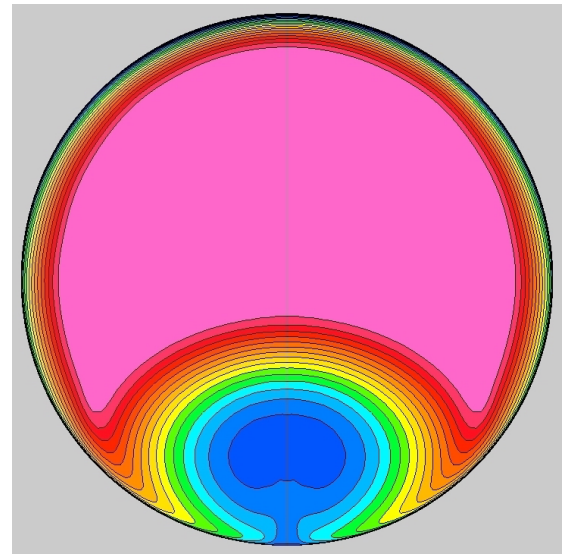

Figure 24. Structured CFD total pressure recoveries at the engine face (baseline configuration, Mach 0.80 at throat)

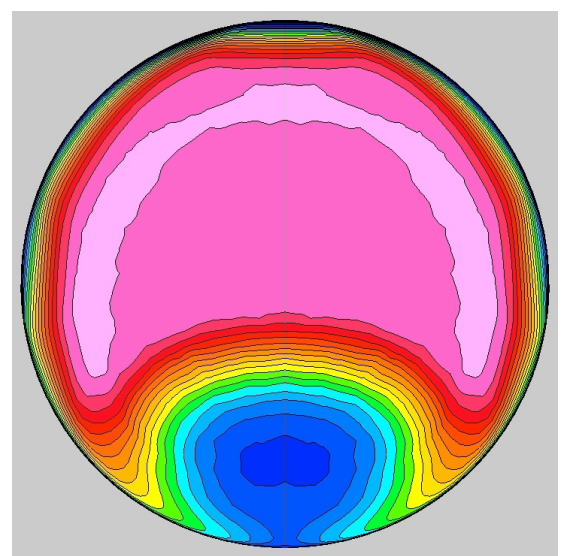

Figure 25. Unstructured CFD total pressure recoveries at the engine face (baseline configuration, Mach 0.78 at throat)
Total pressure distributions at the engine face are presented in Figures 23-25 as contour plots. The three contour plots are, respectively, for the experimental rake data, the structured CFD solution, and the unstructured CFD solution, all very close to the Mach 0.8 throat condition. All three figures use the color scale shown in Figure 23. Note the round hole for the centerbody in Figure 23, not modeled in CFD.

All three plots show a large region of reduced recovery of similar size and depth near the bottom of the engine face. This corresponds to a separated flow region described later, in Section 5.10. The CFD calculations appear to predict a slightly different shape with deeper total pressure losses than shown by experiment. This difference may be due to the absence of the centerbody, which may "push down" the yellow contours in Figure 23. But also note that the S-A turbulence model, used in these calculations, has been shown to over-predict the sizes of separation bubbles in certain cases. ${ }^{23}$

The structured and unstructured solutions disagreed slightly on what exit pressure was required on the outflow boundary to generate a given throat Mach number, as shown in Figure 26.

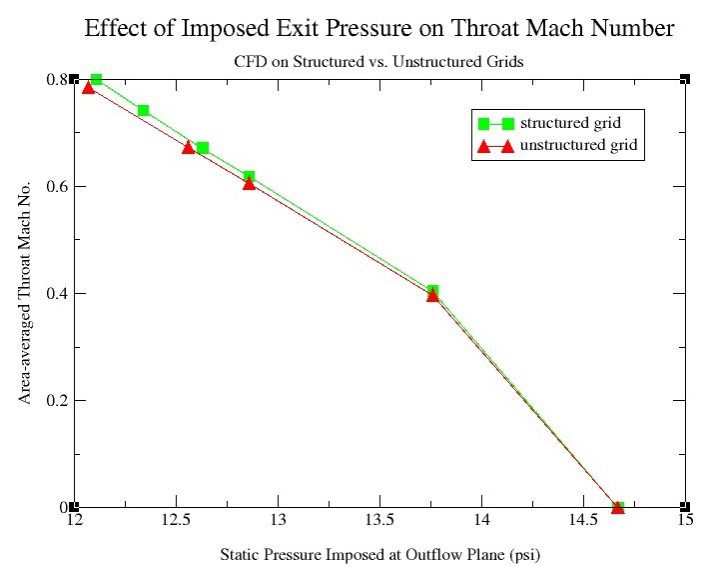

Figure 26. Effect of exit pressure on throat Mach number in CFD calculations

\subsection{Comparisons between CFD and Experiment: VG170 Configuration}

Figure 27 shows total pressure recoveries at the engine face for the VG170 duct. Experiment and unstructured Wind-US show the same trend and agree fairly well.

Figure 28 shows DC60 values for the VG170 duct. As expected, the distortions are dramatically lower than those for the baseline configuration (Figure 22) due to the flow control provided by the vane effectors. The unstructured Wind-US results agree very well with experiment. 


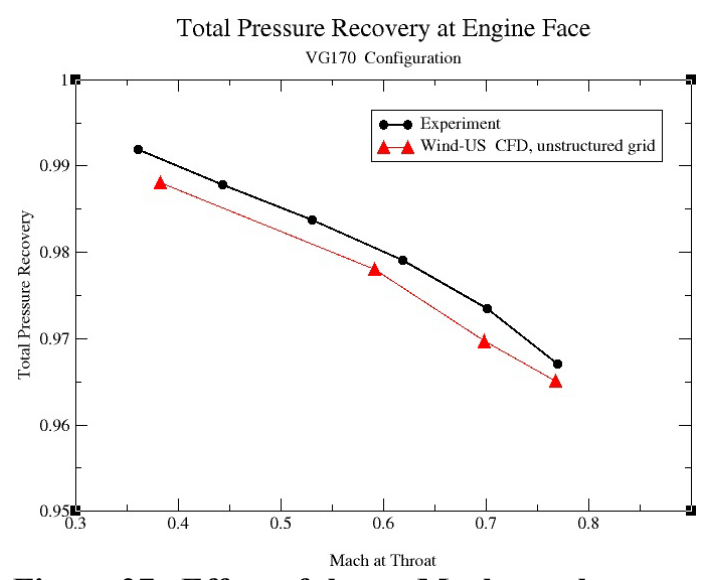

Figure 27. Effect of throat Mach number on total pressure recovery at the engine face - VG170 configuration

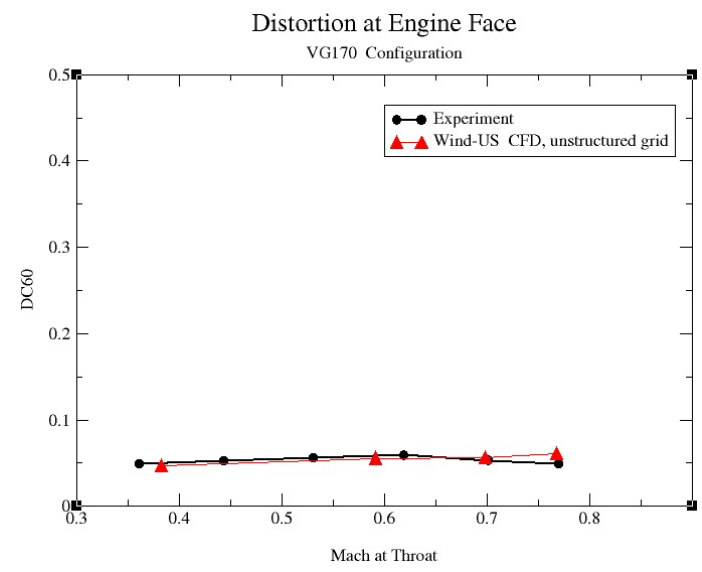

Figure 28. Effect of throat Mach number on DC60 distortion at the engine face - VG170 configuration

Figures 29 and 30 present contour plots of the total pressure at the engine face for a throat Mach number of 0.77. Both figures use the color scale shown in Figure 29 (and 23). The general shapes of the CFD contours appear similar to the experimental contours. Both CFD and experiment show that the addition of the vane effectors has driven the lower recoveries around the sides of the duct and toward the top.

\subsection{Modeling Errors and Uncertainties}

Several shortcomings in the current CFD approach introduced error and uncertainty as defined in References [4] and [20].

One source of error was to not include the centerbody in the CFD model. The cross-sectional area of the centerbody was assumed to be insignificantly small, being about $7 \%$ of the engine face. It is not known

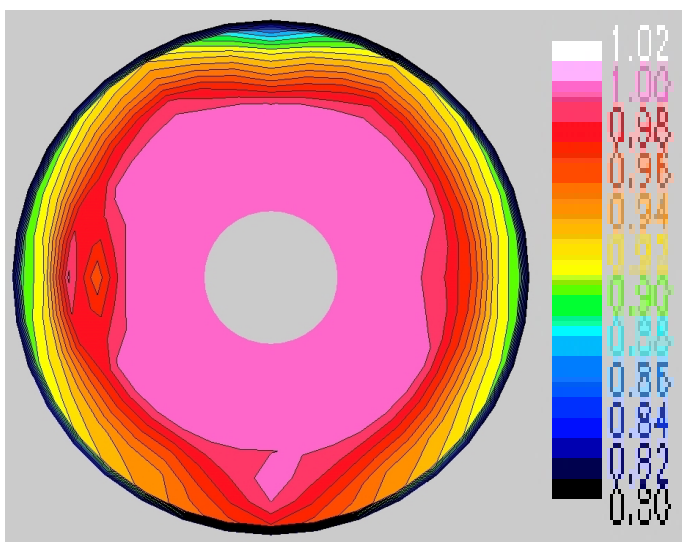

Figure 29. Experimental total pressure recoveries at the engine face (VG170 configuration, Mach 0.77 at throat)

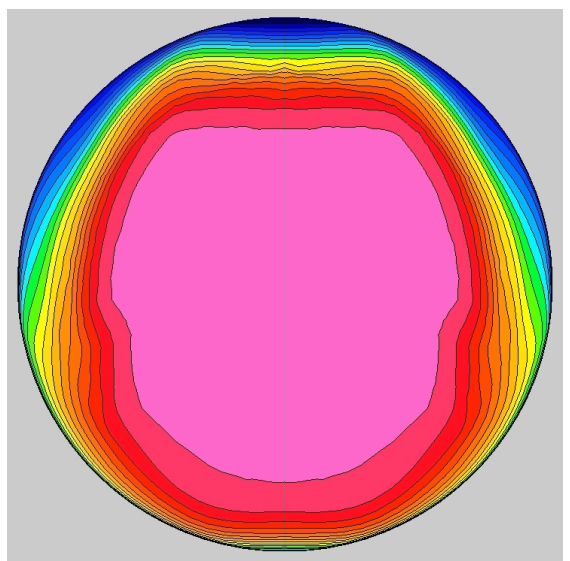

Figure 30. Unstructured CFD total pressure recoveries at the engine face (VG170 configuration, Mach 0.77 at throat)

what effect the addition of the centerbody would have on the computed recoveries and distortions.

Weaknesses in the turbulence model are a source of uncertainty in most CFD calculations. For the current study, the S-A model was used because it alone is common to both the structured and unstructured algorithms in Wind-US. Large flow separations, prominent in the baseline S-duct, are a challenge for turbulence models. As mentioned in Section 5.7, S-A has been shown to over-predict the size of separation regions in some cases.

To obtain an indication of the possible size of the turbulence modeling uncertainty, one flow condition was calculated using the Menter SST model. The SST model was designed with the intention of improving predictions for flow in adverse pressure gradients, ${ }^{24}$ the situation that occurred in the baseline duct. A total pressure recovery predicted using SST is plotted in Figure 21 as an isolated 
square. This data point is closer to the experimental values than the S-A calculations are. However, Figure 22 above similarly plots an isolated square for DC60. Here, the SST model was further away from experiment than was S-A. Therefore, for this minimal comparison, there is no clear winner between the two turbulence models. However the magnitude of the variations in recovery and DC60 give an idea of the uncertainty introduced by turbulence modeling.

In the M2129 experiments, a small amount of flow unsteadiness occurred, as measured at the engine face by 8 pressure transducers located at $67 \%$ of the engine face radius, spaced $45^{\circ}$ apart. The rms values measured over time from the 8 transducers were used to compute an unsteadiness parameter $\mathrm{Pt}_{\mathrm{rms}} / \mathrm{Q}$ discussed in Reference [5]. This parameter reached a high of about $2.5 \%$ for the baseline configuration at the highest Mach condition. However, the CFD calculations were run in steady-state mode (not time accurate) in order to shorten calculation times, a common but small modeling error.

The outflow boundary condition imposed a uniform static pressure across the outflow plane, a small modeling error. A variable static pressure option would have been more physical, but was not available for the unstructured algorithm. Alternatively, the straight section at the duct exit might have been lengthened.

Two post processors may have introduced some sources of error involving the manner of integrating total pressures and computing DC60. CFPOST was used to compute recoveries. For as yet unknown reasons, CFACE computed recoveries that disagreed slightly with those of CFPOST (on the order of $0.5 \%$ ). In addition, the procedure for computing distortion on unstructured grids had an extra step, which was to use CFPOST to interpolate onto a structured grid (for input to CFACE). The choice of structured grid resolution slightly affected DC60. A dense grid dimensioned 56 × 57 was used.

\subsection{CFD Flow Visualization: Baseline Configuration}

Images of the flow fields for the baseline configuration were produced for the highest Mach number condition ( 0.8 at throat). Contour plots of Mach number, static pressure, and total pressure are presented as well as depictions of streamlines and simulated surface oil traces.

As expected, the flow field exhibited massive separation downstream of the bend. Figures 31-33 show plots of Mach number, static pressure, and total pressure in the symmetry plane as computed on the unstructured grid. Note that the color scales in Figures 32 and 33 are labeled in psi.

Figure 34 shows simulated oil traces on the baseline, structured grid. Figure 35 shows the equivalent for the unstructured grid. The two figures reveal the same major flow features. The flow is drawn from the sides of the duct and down into the bottom.

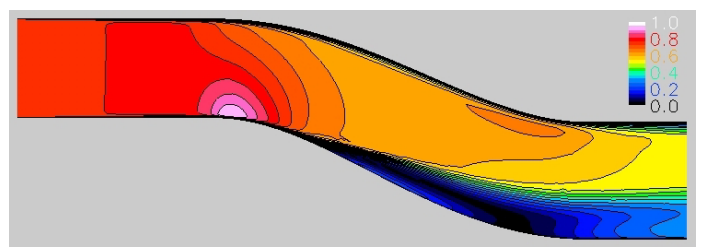

Figure 31. Mach contours, baseline configuration, unstructured Wind-US CFD

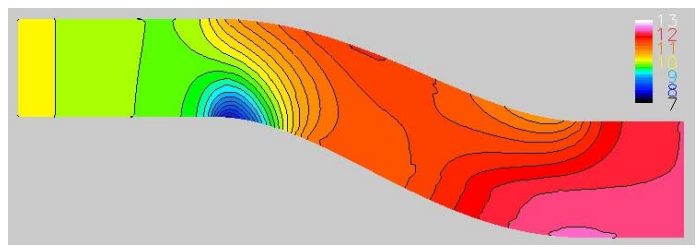

Figure 32. Static pressure contours, baseline configuration, unstructured Wind-US CFD

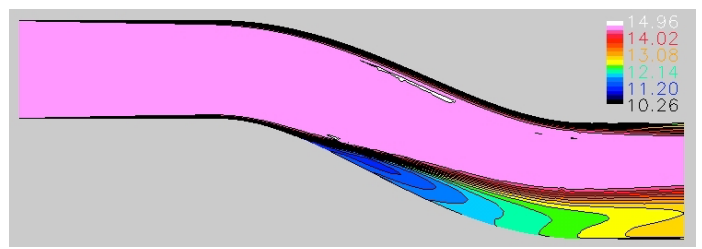

Figure 33. Total pressure contours, baseline configuration, unstructured Wind-US CFD

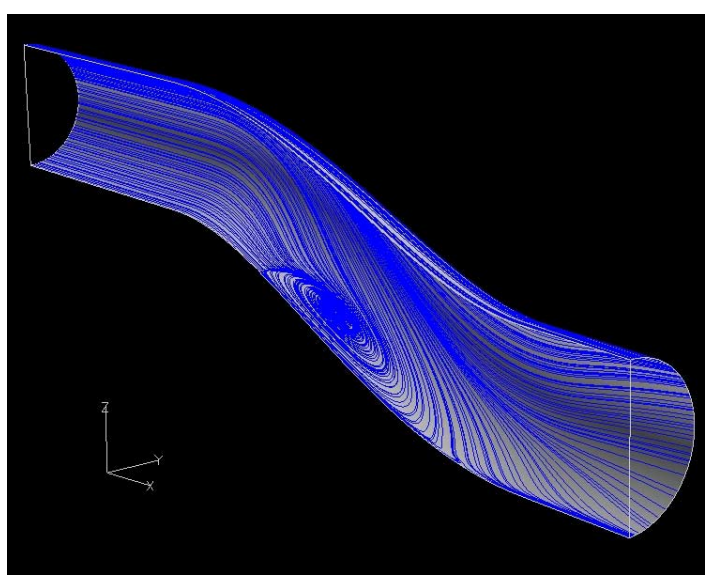

Figure 34. Simulated oil traces, baseline configuration, CFD on structured grid 


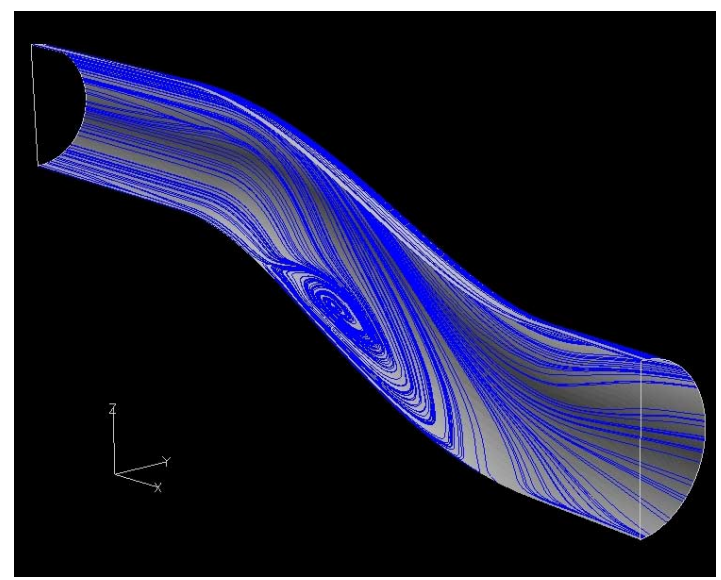

Figure 35. Simulated oil traces, baseline configuration, CFD on unstructured grid

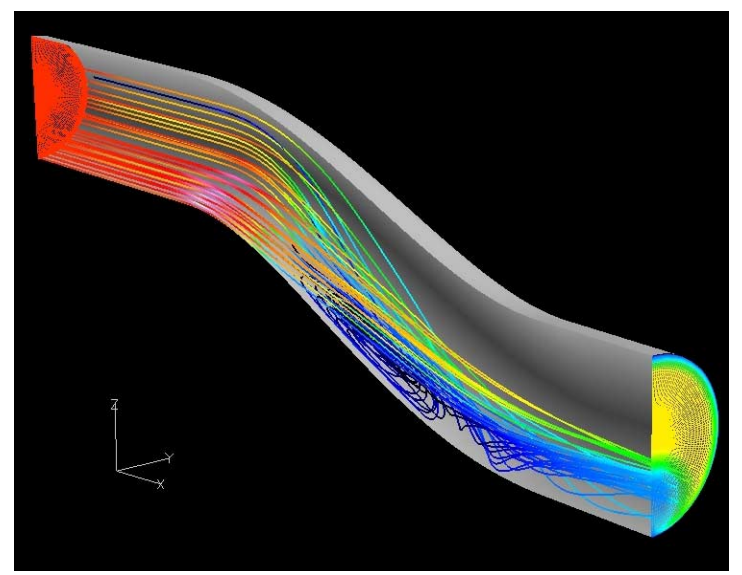

Figure 36. Streamlines, baseline configuration, CFD on structured grid

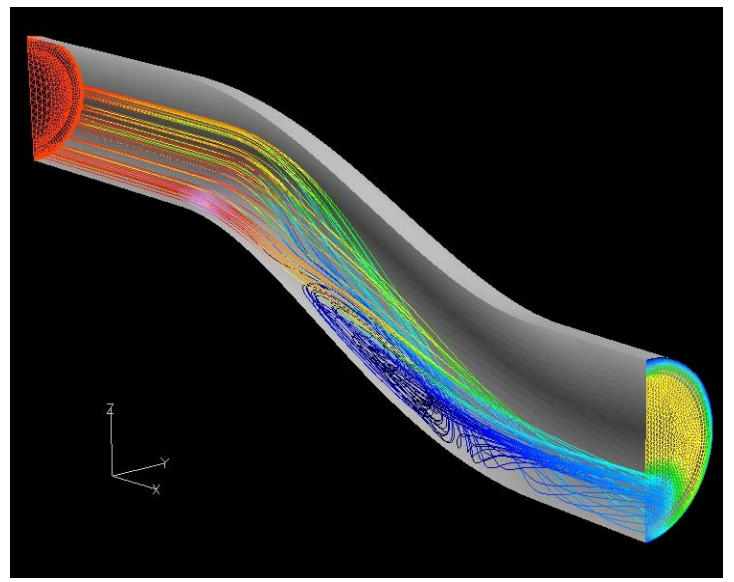

Figure 37. Streamlines, baseline configuration, CFD on unstructured grid
Figures 36 and 37 show streamlines as computed by the structured and unstructured runs, respectively. The streamlines are colored by Mach number. Note that there are discrepancies between the two figures due to the use of differing sets of seed points for the streamlines. In both figures, a separation vortex is seen at the bottom of the duct, which leads to large total pressure loss and distortion at the exit plane. Flow along the wall is drawn from the side of the duct down into the bottom, as was seen in the simulated oil flow traces.

\subsection{CFD Flow Visualization: VG170 Configuration}

Images of the flow fields for the VG170 configuration were produced for the highest throat Mach number condition ( 0.77 at throat). Contour plots of Mach number, static pressure, and total pressure are presented as well as depictions of streamlines and simulated surface oil traces.

Figures 38-40 show plots of Mach number, static pressure, and total pressure in the symmetry plane as computed on the unstructured grid. The three figures show that the vane effectors counteracted the formation of the duct vortex seen in the baseline cases.

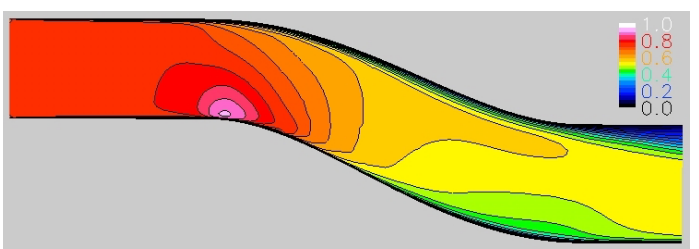

Figure 38. Mach contours, VG170 configuration, unstructured Wind-US CFD

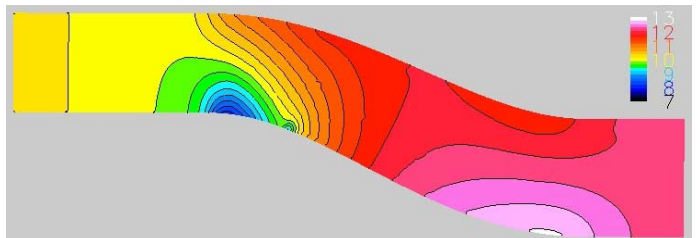

Figure 39. Static pressure contours, VG170 configuration, unstructured Wind-US CFD

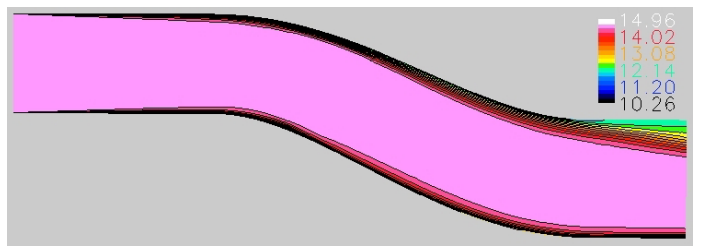

Figure 40. Total pressure contours, VG170 configuration, unstructured Wind-US CFD 


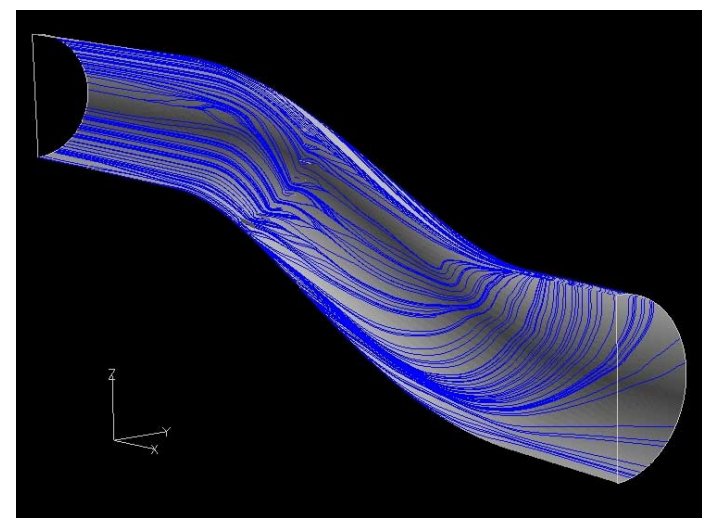

Figure 41. Simulated oil traces, VG170 configuration, CFD on unstructured grid

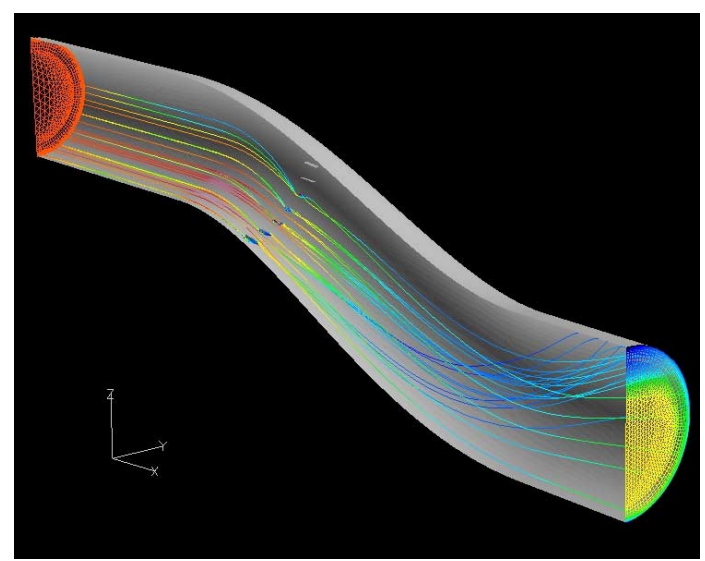

Figure 42. Streamlines, VG170 configuration, CFD on unstructured grid

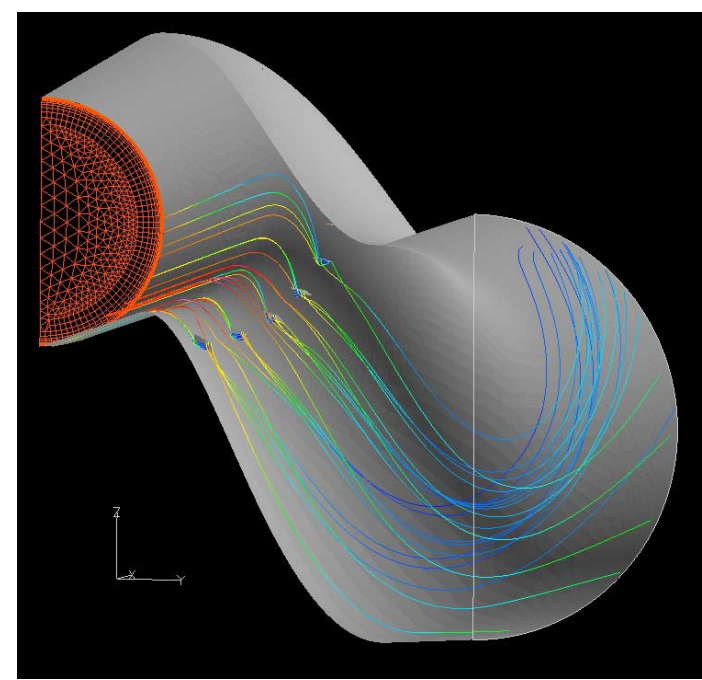

Figure 43. Streamlines, VG170 configuration, CFD on unstructured grid
Figure 41 shows simulated oil traces on the VG170 unstructured grid. With the addition of the vane effectors, low-energy flow is no longer pulled down into the bottom of the duct but is instead directed toward the top.

Streamlines inside the duct, colored according to Mach number, are shown in Figure 42. Figure 43 shows the same streamlines from another direction. One can see how the vane effectors steer the flow up around the sides distributing the low energy flow. This is opposite to what was seen for the baseline duct.

\section{CONCLUSIONS}

An approach to conducting the complete CFD process using unstructured grids with Wind-US was described. Wind-US computed flow fields in a diffusing S-duct with and without flow control, for a range of throat Mach numbers approaching Mach 1. Calculations of total pressure recovery and distortion at the engine face, with and without flow control, agreed well with experiment. Some issues that may have introduced modeling errors were identified. Timings on two computer platforms were given.

The validation case emerging from the current study should be expanded to include comparisons with experiment of computed static pressures along the duct walls; grid resolution sensitivity studies; zone partitioning sensitivity studies; investigation of alternative convergence criteria; comparison of alternative turbulence models (when available in both structured and unstructured modes); running the unstructured solver on the hexahedral grid (i.e., the structured grid) for direct comparison with the structured solver; and the centerbody should be included for more fidelity. The $95 \%$ confidence intervals on the experimental total pressure recoveries and distortions, essentially error bars, are available and should be added to the plots for more thorough comparison with CFD. The discrepancies between the CFPOST and CFACE integrated quantities should be investigated. The grid generation process with the proprietary MADCAP should be started from scratch using an IGES file and a newer version of AFLR3 for a more automated process.

In the future, additional turbulence models, boundary conditions, and algorithms will be put into Wind-US. The SST turbulence model is expected to become available to the unstructured solver soon. Currently existing unstructured grid flow solvers other than ICAT may be incorporated as well. It is hoped that the M2129 S-duct will be helpful in validating future releases of Wind-US and in aiding new users learn how to use the software. 


\section{REFERENCES}

${ }^{1}$ Nelson, C.C. and Power, G.D., "CHSSI Project CFD-7: The NPARC Alliance Flow Simulation System," AIAA-2001-0594, Jan. 2001.

${ }^{2}$ NPARC Alliance, "Wind-US User's Guide," Oct. 2003.

${ }^{3}$ Slater, J.W., Abbot, John M., Cavicchi, R.H., "Validation of WIND for a Series of Inlet Flows," AIAA-2002-0669, 2000.

${ }^{4}$ AIAA, "Guide for the Verification and Validation of Computational Fluid Dynamics Simulations," AIAA G-077-1998, 1998.

${ }^{5}$ Anderson, B.H., Gibb, J., "Vortex Generator Installation Studies on Steady State and Dynamic Inlet Distortion,” AIAA-1996-3279, 1996.

${ }^{6}$ Bray, T.P., Weir, B., Gibb, J., "Experimental Evaluation of Inlet Distortion Management at Flight Reynolds Number (M2129 Phase 9)," DERA/MSS/MSFC2/CR990134, Jun. 30, 1999.

${ }^{7}$ Hamstra, J.W., Miller, D.N., Truax, P.P., Anderson, B.H., "Active Inlet Flow Control Technology Demonstration," ICAS-2000-6.11.2, 2000.

${ }^{8}$ Anderson, B.H., Baust, H.D., Agrell, J., "Management of Total Pressure Recovery, Distortion and High cycle Fatigue in Compact Air Vehicle Inlets," NASA/TM-2002-212000, Dec. 2002.

${ }^{9}$ Anderson, B.H., Miller, D.N., Gridley, M.C., Agrell, J., "The Role of Design-of-Experiments in Managing Flow in Compact Air Vehicle Inlets," NASA/TM2003-212601, May 2003.

${ }^{10}$ Liu, Z., Lynch, E., "ICAT User Manual-Version 02.09," HyPerComp, Inc.

${ }^{11}$ BCFD Development Team, "BCFD Users's Guide," The Boeing Company Phantom Works, Mar. 27, 2002.

${ }^{12}$ “Common File Programmers Guide," The Boeing Company Phantom Works, Oct. 15, 2003.
${ }^{13}$ Marcum, D.L. and Weatherill, N.P., "Unstructured Grid Generation Using Iterative Point Insertion and Local Reconnection," AIAA Journal, Vol. 33, No. 9, pp. 16191625, Sep. 1995.

${ }^{14}$ ICEM-CFD Engineering, "ICEM CFD/CAE Output Interfaces: WIND (CFF)," URL:

http://www.icemcfd.com/interfaces/wind.html [cited 3 Nov. 2003].

${ }^{15}$ Rumsey, C.L., Poirier, D.M.A., Towne, C.E., "CFD General Notation system: A User's Guide to CGNS," NASA/TM-2001-211236, Oct. 2001.

${ }^{16}$ NPARC Alliance, “CFPOST User’s Guide,” 2002.

${ }^{17}$ AGARD FTP Working Group 13, "Air Intakes for High Speed Vehicles,” AR-270, Sept. 1991.

${ }^{18}$ Private communication with Dr. Bernhard Anderson, Senior Researcher, NASA Glenn Research Center, October 2003.

${ }^{19}$ Seddon, J., Goldsmith, E.L., Intake Aerodynamics, AIAA, Washington, D.C, 1985, p.296.

${ }^{20}$ Slater, J.W., "Tutorial on CFD Verification and Validation," [online], URL:

http://www.grc.nasa.gov/WWW/wind/valid/tutorial/tutori al.html [cited 3 Nov. 2003].

${ }^{21}$ Dudek, J.C., "Vortex Generator Modeling Capability in the WIND Code," draft report, Dec. 2001.

${ }^{22}$ Dudek, J.C., "VG-td118-val: Vortex Generator Model Validation for Subsonic Diffuser Flow," draft report, Aug. 2003.

${ }^{23}$ Wilcox, D.C., Turbulence Modeling for CFD - Second Edition, DCW Industries, La Cañada, CA, Mar. 2000, pp. $115,117$.

${ }^{24}$ Menter, F.R., "Two-Equation Eddy-Viscosity Turbulence Models for Engineering Applications," AIAA Journal, Vol. 32, No. 8, Aug. 1994, p.1598. 


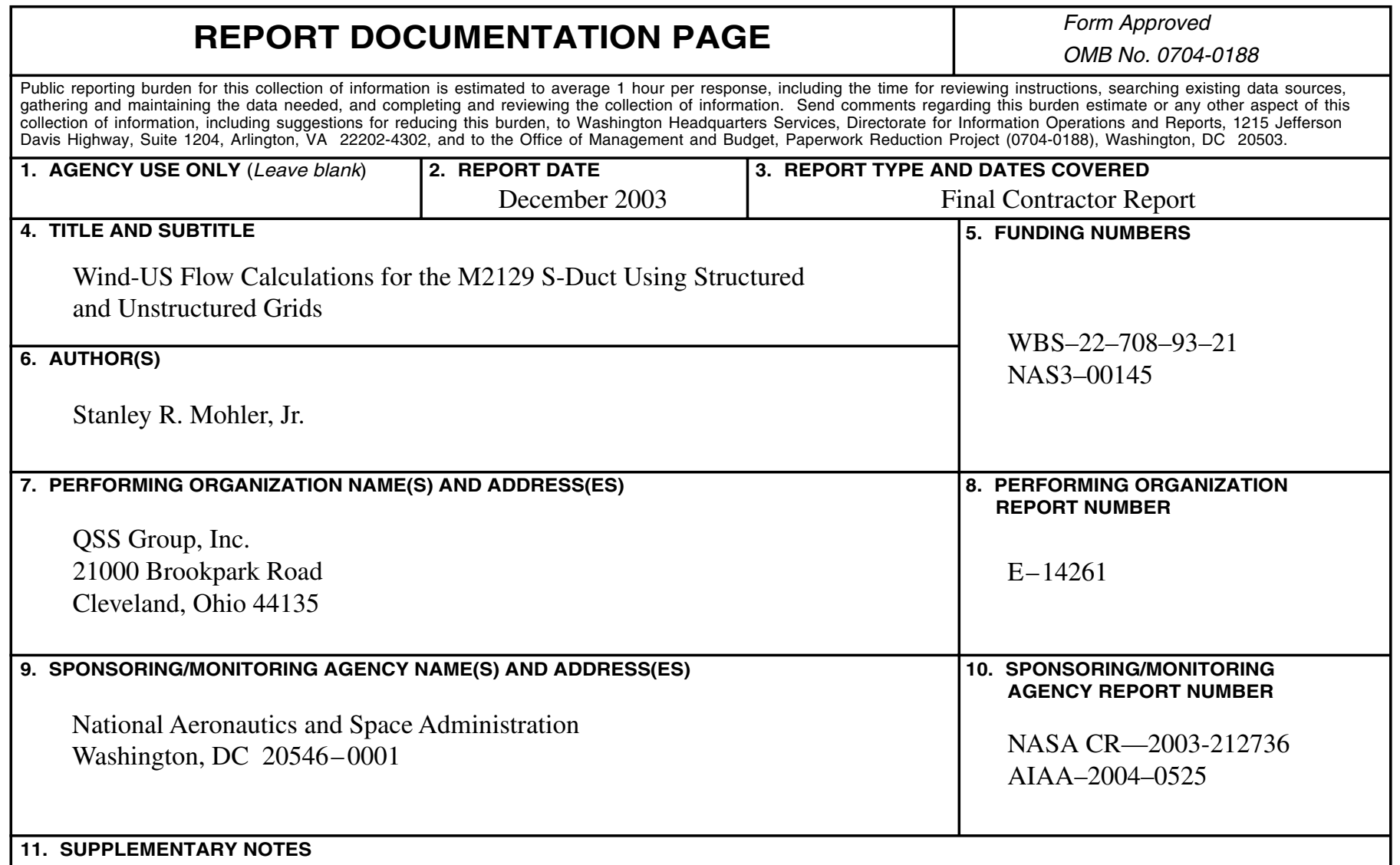

Prepared for the 42nd Aerospace Sciences Meeting and Exhibit sponsored by the American Institute of Aeronautics and Astronautics, Reno, Nevada, January 5-8, 2004. Project Manager, David A. Sagerser, Aeropropulsion Research Program Office, NASA Glenn Research Center, organization code 0141, 216-433-2172.

12a. DISTRIBUTION/AVAILABILITY STATEMENT

12b. DISTRIBUTION CODE

Unclassified - Unlimited

Subject Category: 34

Distribution: Nonstandard

Available electronically at http://gltrs.grc.nasa.gov

This publication is available from the NASA Center for AeroSpace Information, 301-621-0390.

13. ABSTRACT (Maximum 200 words)

Computational Fluid Dynamics (CFD) flow solutions for the M2129 diffusing S-duct with and without vane effectors were computed by the Wind-US flow solver. Both structured and unstructured 3-D grids were used. Without vane effectors, the duct exhibited massive flow separation in both experiment and CFD. With vane effectors installed, the flow remained attached and aerodynamic losses were reduced. Total pressure recovery and distortion near the duct outlet were computed from the solutions and compared favorably to experimental values. These calculations are part of a validation effort for the Wind-US code. They also provide an example case to aid engineers in learning to use the Wind-US software.

14. SUBJECT TERMS

Computational fluid dynamics; Unstructured grids; Inlet flow; Vortex generators 15. NUMBER OF PAGES 23

Computational fluid dynamics, Unstructured grids, Inlet flow; Vortex generators

\begin{tabular}{|c|c|c|c|}
\hline $\begin{array}{c}\text { 17. SECURITY CLASSIFICATION } \\
\text { OF REPORT } \\
\text { Unclassified }\end{array}$ & $\begin{array}{c}\text { 18. SECURITY CLASSIFICATION } \\
\text { OF THIS PAGE } \\
\text { Unclassified }\end{array}$ & $\begin{array}{c}\text { 19. SECURITY CLASSIFICATION } \\
\text { OF ABSTRACT } \\
\text { Unclassified }\end{array}$ \\
\hline
\end{tabular}

